\title{
Color Doppler ultrasound in diagnosis of placenta accreta
}

\section{Original Article}

\author{
Hesham M. Borg', Ahmed M. Ossman', Hesham A. Salem ${ }^{1}$, Mahmoud \\ El-Hemedi ${ }^{3}$, Khaled El-Shafie ${ }^{2}$ and Reda A. Alarabawya ${ }^{2}$
}

${ }^{1}$ Department of Obstetrics and Gynecology, Faculty of Medicine, Tanta University, Egypt.

${ }^{2}$ Department of Radiology, Faculty of Medicine, Tanta University, Egypt.

${ }^{3}$ Department of Obstetrics and Gynecology, Zawya University, Lybia

\begin{abstract}
Background: Placenta accreta is a major source of maternal morbidity and mortality and is currently the major reason for peripartum hysterectomy. The strict etiology is indefinite, but it has been postulated to be correlated to the injury of the decidua basalis, which allows for the placental attack into the myometrium.

Purpose: To evaluate the accuracy of color Doppler ultrasonography in the diagnosis of placenta accreta and to compare it with the diagnostic accuracy of both 2D Ultrasonography and MRI.

Material and Methods: A prospective study was done at Obstetrics and Gynecology Department of Tanta University Hospital, Egypt. The study included 100 patients with suspected placenta accreta based on 2D ultrasonography, color Doppler and MRI. The intraoperative findings of each case were compared with the preoperative imaging findings.

Results: Sensitivity for the diagnosis of placenta accreta was (100\%) for color Doppler ultrasound, (93.7\%) for 2D ultrasound and (75\%) for MRI. Specificity was (66.6\%) with color Doppler and (77.7\%) for 2D ultrasound and (55.5\%) for MRI. The highest positive predictive value (PPV) was found in 2-D ultrasound (88\%), MRI had the lowest PPV (75\%), while color Doppler had 84\%PPV. Negative predictive value (NPV) was $(100 \%),(87.5 \%),(55.5 \%)$ for color Doppler, 2D ultrasound and MRI, respectively.

Conclusion: Color Doppler Ultrasound is the most accurate imaging modality in the diagnosis of placenta accreta. Its accuracy, when combined with 2D ultrasound, would increase and provides the best available modality for diagnosis of placenta accreta.
\end{abstract}

Key Words: $\beta$-HCG, ectopic pregnancy, laparoscope, methotrexate.

Received: 17 May 2018, Accepted: 12 June 2018

Corresponding Author: Hesham Salem, Department of Obstetrics \& Gynecology, Faculty of Medicine, Tanta University, Egypt, Tel.: 01223488672, E-mail: prof.hesham_salem@hotmail.com

ISSN: 2090-7265, August 2018, Vol.8, No. 3

\section{INTRODUCTION}

The word morbidly adherent placenta implies an atypical implantation of the placenta into the uterine wall and has been used to express placenta accreta, increta, and percreta. Placenta accreta is a placenta where the placental villi stick on directly to the myometrium. Placenta increta is a placenta where the placental villi attack into the myometrium and placenta percreta is a placenta where the villi invade through the myometrium and into serosa ${ }^{[1]}$.

Placenta accreta is a major source of maternal morbidity and mortality and is currently the major reason for peripartum hysterectomy ${ }^{[2]}$. The strict etiology is indefinite, but it has been postulated to be correlated to the injury of the decidua basalis, which allows for the placental attack into the myometrium. The barrier role of the decidua is missing in this circumstances, and the invasive trophoblasts may attack the myometrium to varying lowest point, from the most shallow (placenta accreta) to deeper myometrial invasion (placenta increta), with breach of the uterine serosa and may be attack neighboring organs ${ }^{[3]}$.

Risk factors for placenta accreta include previous cesarean delivery, placenta previa maternal age over 35 , uterine instrumentation and intrauterine scar, all of which may be connected with injuring to or lack of the decidua basalis. ${ }^{[4]}$ Within the occurrence of these risk factors, the obstetricians have a high index of doubt for placenta accreta and take proper protection. In exacting, this condition must be integrated into the differential diagnosis in women with previous caesarean sections and anterior low-lying placentas ${ }^{[5]}$.

The pathogenesis of placenta accreta is not obvious ; on the other hand, there have been numerous 
theories anticipated. Atypical vascularization resulting from the scar development following surgery with resulting localized hypoxia leading to both imperfect decidualization and extreme trophoblastic invasion appears to be the most famous or at least it supports the hypothesis to date, explaining the pathogenesis of placenta accreta at this point ${ }^{[6]}$.

The majority of patients with placenta accreta are asymptomatic. Symptoms associated with placenta accreta may include vaginal hemorrhage and cramp. These findings are mainly seen in relation to placenta previa, which is the strongest risk factor for placenta accreta. Although rare, acute abdominal pain and hypotension is considered a potentially disastrous appearance owing to hypovolemic shock from uterine rupture secondary to placenta percreta. These serious circumstances can take place at any time throughout gestation from the first trimester to full term gestations in the absence of labor ${ }^{[7]}$.

Placenta accreta may be linked with serious internal bleeding that can lead to maternal and /or fetal death. Placenta percreta may make a possible uterine rupture, or it may attack the bladder causing hematuria. Maternal death and fetal death takes place in just about $9.5 \%$ of cases $^{[8]}$. There has been a significant increase in the occurrence of placenta accreta over the past numerous decades. The most important reason for this increase is the elevated rise in the rates of cesarean deliveries ; cesarean deliveries and placenta praevia are recognized risk factors for placenta accrete $^{[9]}$. Placenta accreta is becoming an increasingly frequent problem of pregnancy. Likely related to the increasing rate of cesarean delivery over the last five decades, placenta accreta occurs in about $1: 1000$ deliveries with a reported range from $0.04 \%$ rising up to $0.9 \%{ }^{[10]}$.

At this occasion, no antenatal diagnostic method gives the clinician $100 \%$ assurance of either ruling in or ruling out the existence of placenta accreta. The definitive diagnosis of placenta accreta is frequently ended postpartum on hysterectomy specimens when an area of accretion shows chorionic villi direct make contact with the myometrium and absence of deciduae $^{[11]}$.

Placenta accreta must be supposed in women who have both a placenta praevia, particularly anterior and a history of cesarean or further uterine operation. The most significant factor affecting outcome is the prenatal diagnosis of this circumstance. It gives the chance to make a delivery chart that correctly anticipates the predictable blood loss and other probable complications of delivery. In addition, it gives the chance for electively timing the process since avoidance of complications perfectly requires the presence of a multidisciplinary surgical team ${ }^{[12]}$
Antenatal ultrasound is the method of choice used to establish the diagnosis and direct clinical management ${ }^{[13]}$. Second and third trimester gray-scale 2D sonographic characteristics comprise loss of continuity of the uterine wall, numerous vascular lacunae (irregular vascular spaces) inside placenta, giving "Swiss cheese" look nearby to the placental implantation site, lack of a hypo echoic margin (myometrial zone) between the placenta and the myometrium, bulging of the placental and myometrial location into the bladder ${ }^{[14]}$.

Color Doppler appears to improve the diagnostic accuracy of grey-scale ultrasound techniques and must be used freely in situations where there is a high guide of doubt for placenta praevia ${ }^{[15]}$. Three-dimensional power Doppler was targeted to detect angio construction in the basal and lateral views of the placenta. The ultrasound findings were analyzed with reference to the final diagnosis completed during cesarean delivery. Three-dimensional power Doppler may be valuable as a complementary method for the antenatal diagnosis or elimination of placenta accrete ${ }^{[16]}$. Transvaginal ultrasound is the secure presence of placenta praevia and is more precise than trans-abdominal ultrasound in locating placenta ${ }^{[17]}$.

Ultrasonography and MRI are equivalent in diagnosing placenta accreta. The latter has additional value in detecting the depth of placental invasion and depicting posterior placenta accrete. On the other hand, there is inadequate proof to support routine MRI scanning of patients with sonographically suspected placenta accreta to improve management and conclusion. MRI is often recommended when ultrasound findings are questionable ${ }^{[18]}$.

\section{D Ultrasonographic features of morbidly adherent placentas:}

1-Loss of Retro-placental sonolucent zone : it is usually taking place as clear zone between the placenta and myometrium. This area is observed from 12 weeks and is supposed to be associated with the dilated vessels of the decidua basalis. Lack and progressive loss of the deciduas have been proposed and established histologically in placenta accrete ${ }^{[19]}$.

2-Vascular lacunae : they provide the placenta a "moth-eaten" or "Swiss cheese" appearance and frequently have unstable flows within them. They as well appear as irregular and more linear rather than rounded and smooth bordered. They do not have the extremely echogenic boundaries that typical sinuses have ${ }^{[12]}$. The presence of this sonographic sign has been reported to be associated with the maximum positive prognostic value for placenta accreta especially when recognized in second and third trimesters ${ }^{[20]}$. 
3- Myometrial thinning : progressive thinning of the retro-placental myometrium indicates the proximity of the placental tissue to the peritoneal serosa or adjacent viscera, chiefly the bladder. Segmental myometrial thinning of, $1 \mathrm{~mm}$ is suggestive of an adherent placenta $^{[21]}$.

4- Interruption of the bladder border : Lack of myometrial tissue might result in thinning or disturbance of the vesicouterine interphase, which was found to be linked with greater compromise with placenta accrete $^{[22]}$. This can give a sign of asymmetrical interruptions of the bladder wall-uterine interface or a sensation that the bladder wall is bulging into the uterine wall. This characteristic is an accurate sign for placenta accreta but with poor sensitivity ${ }^{[22]}$.

\section{Color Doppler imaging:}

Color and power Doppler propose a higher specificity in the diagnosis of placenta accreta and in particular, the depth of invasion. A pattern of confused blood flow extend from the placenta into the nearby tissues has been reported in placenta accrete ${ }^{[23]}$. Other measures consist of focal or diffuse intra-parenchymal placental lacunar flow, vesicouterine serosa interphase hypervascularity, prominent retro placental venous complex, and loss of retro placental Doppler vascular signals ${ }^{[24]}$.

Color Doppler ultrasonography appears to be more revealing than power Doppler ultrasonography, as it is capable to exhibit the speed and character of the flow ${ }^{[25]}$. High velocity and turbulent flow are always associated with placenta accreta. The placental vessels are frequently large and this can only be selected by using color Doppler rather than power Doppler Ultrasonography ${ }^{[26]}$.

\section{The color Doppler criteria suggestive for placenta accreta include:}

1- A diffuse or focal lacunar flow pattern exhibit diffusely dilated vascular channels spread all over the placenta. The high- velocity pulsatile venous-type flow was found in these spaces ${ }^{[27]}$.

2- The absence of sub placental vascular signals in the areas missing the marginal sub placental hypo echoic zone $^{[28]}$.

3- Interphase hypervascularity with abnormal blood vessels connecting the placenta to the bladder with high diastolic arterial blood flow ${ }^{[12]}$.

\section{Magnetic resonance imaging (MRI):}

Ultrasonography and MRI are equivalent in diagnosing placenta accreta. The latter has additional value in detecting the depth of placental invasion and depicts posterior placenta accrete, on the other hand, there is insufficient proof to support routine MRI scanning of patients with sonographically suspected placenta accreta to get better management and result. MRI is often suggested when ultrasound findings are questionable ${ }^{[18]}$.

If the ultrasound findings are not considered definitive or the placenta is located on the posterior wall, magnetic resonance imaging MRI can be performed. Magnetic resonance imaging findings considered doubtful for the presence of placenta accrete include placental heterogeneity, uterine bulging, tenting of the bladder, heterogeneous signal strength within the placenta, mass effect of the placenta into the underlying bladder or extending away from the normal uterine contour, destruction of the myometrial zone, and a beading nodularity inside the placenta ${ }^{[29]}$. Dark intra-placental bands can also be seen, appearing as nodular or linear areas of low signal strength on T2-weighted images ${ }^{[29]}$.

MRI has proved most helpful when the placenta is located posteriorly. Besides being safe for both mother and fetus, MRI requires slight adjustment in the way of preparation. Unfortunately, it lacks portability and is more costly to make than ultrasound. ${ }^{[29]}$

\section{PATIENTS AND METHODS}

In a prospective cross-sectional clinical study done at Obstetrics and Gynecology Department of Tanta University Hospital, Egypt, 100 pregnant women seeking for antenatal care were included during the period from July 2014 to February 2015.

The 100 pregnant women with suspicious history and ultrasonic findings of placenta accreta were included in the study. The suspected placenta accreta is based on 2D Ultrasonography, Color Doppler, and MRI. The patients have a history of C.S and the ultrasound scan revealed anterior placenta previa. The inclusion criteria included all pregnant women on third-trimester gestation with abnormal placental invasion including (patients with placenta previa anteriorly located and attached on a previous caesarian section scar, placenta attached on a previous uterine scar like myomectomyor hysterotomy and history of placental retention during previous delivery) and exclusion criteria include primigravida, accidental hemorrhage, gestational age less than 28 weeks, and if the placenta is located posteriorly.

All women were subjected to an informed written consent approved by the Ethical Committee of Tanta University Hospital. Compelete history taking, complete general and local examination, routine lab investigations, transabdominal and transvaginal ultrasound after $28^{\text {th }}$ week of gestations with special attention on placenta site and grade, degree of attachment. MRI to detect placental site and degree of placental invasion and color Doppler ultrasound on placental bed. 
The 2D ultrasound, color Doppler and MRI were performed by Obstetricians or Radiologists experienced in the abnormal adherent placenta. The equipment included the Siemens Acuson . X300 premium edition ultrasound (Germany). MRI was performed with a 1.5 Tesla scanner, Siemens, Germany.

The 2D ultrasound, color Doppler, and MRI images were compared with the intraoperative findings for each case. Placenta accreta was defined by clinical criteria at the time of delivery. The placenta was considered normal if it was easily removed during cesarean delivery without any bleeding complications. Ideally, the standard of reference for the diagnosis of the abnormal adherent placenta is confirmation of the final histology after hysterectomy. However, hysterectomy is not always clinically indicated or possible. Therefore, in these cases, pathologic examination was not available and the diagnosis was based on clinical information provided at the time of delivery.

Statistical analysis was performed using statistical software (SPSS V.20). The sensitivity (Se), specificity (Sp), positive predictive value (PPV), and negative predictive value (NPV) were calculated for color Doppler, 2D sonography, and MRI.

\section{RESULTS}

Table 1 : The range and the mean of age, gravidity, parity, and gestational age of studied cases

\begin{tabular}{lccc}
\hline & Range & Mean & S.D \\
\hline Age (years) & $23-38$ & 31.24 & 3.86 \\
Gravidity & $2-11$ & 4.0 & 2.06 \\
& $1-4$ & 1.96 & 0.789 \\
Parity & & & \\
& & & \\
Gestational & $31-39$ & 35.88 & 2.14 \\
age (weeks) & & & \\
\hline
\end{tabular}

Table 1 displays that the mean age of the studied patients was $31.24 \pm 3.86$ years and ranged between 23-38 years. Their gravidity ranged between 2-11 with the mean was $4.0 \pm 2.06$ also their parity ranged between 1-4 with mean parity was $1.96 \pm 0.789$. Regarding gestational age, it was ranged between 31-39 weeks with the mean was $35.88 \pm 2.14$ weeks.

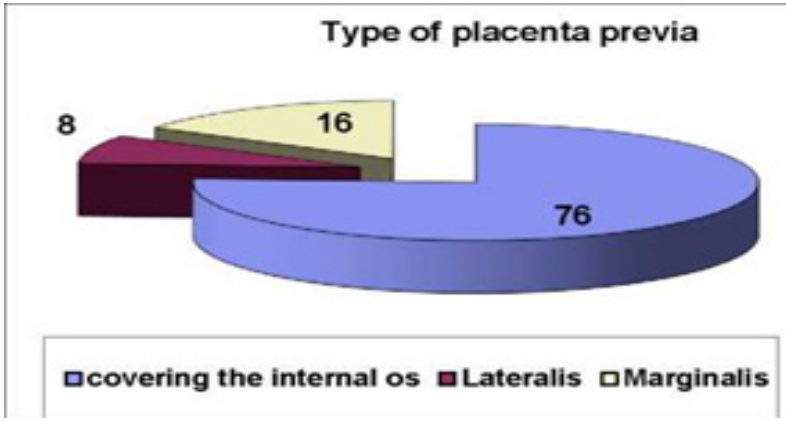

Fig. 1: Distribution of placenta praevia types among cases

Figure 1 shows that in $76 \%$ of the patients, the placenta previa were covering the internal os ; whereas, placenta previa marginalis and lateralis were found in $(16 \%)$ and $(8 \%)$ of the studied patients, respectively.

Table 2: Preoperative diagnosis of placental attachment by color Doppler, 2D ultrasound, MRI between cases

\begin{tabular}{|c|c|c|c|c|c|}
\hline \multicolumn{2}{|c|}{$\begin{array}{c}\text { Radiological } \\
\text { parameter }\end{array}$} & \multirow{2}{*}{$\begin{array}{c}\text { No. } \\
76\end{array}$} & \multirow{2}{*}{$\begin{array}{l}\% \\
76\end{array}$} & \multirow[t]{2}{*}{$\mathrm{X}^{2}$} & \multirow{2}{*}{ P. value } \\
\hline \multirow[b]{2}{*}{ Doppler } & Accreta & & & & \\
\hline & $\begin{array}{c}\text { Not } \\
\text { Accreta }\end{array}$ & 24 & 24 & 13.520 & 0.001 \\
\hline \multirow[b]{2}{*}{ 2D U. S } & Accreta & 68 & 68 & \multirow[b]{2}{*}{12.690} & \multirow[b]{2}{*}{0.001} \\
\hline & $\begin{array}{c}\text { Not } \\
\text { Accreta }\end{array}$ & 32 & 32 & & \\
\hline \multirow[b]{2}{*}{ MR I } & Accreta & 64 & 64 & \multirow[b]{2}{*}{7.480} & \multirow[b]{2}{*}{0.005} \\
\hline & $\begin{array}{c}\text { Not } \\
\text { Accreta }\end{array}$ & 36 & 36 & & \\
\hline
\end{tabular}

Table 2 shows that in preoperative diagnosis using color doppler, $76 \%$ of cases were placenta accreta compared to $24 \%$ placenta not accreta with significant difference between them $(P=0.001)$. Regarding $2 \mathrm{D}$ ultrasound diagnosis, $68 \%$ of cases were accreta, whereas $32 \%$ of them were not accreta, with significant difference between both groups $(0.002)$. When using MRI in preoperative diagnosis, $64 \%$ of the cases were placenta accreta and differed significantly from $36 \%$ of cases who were not accreta $(P=0.005)$.

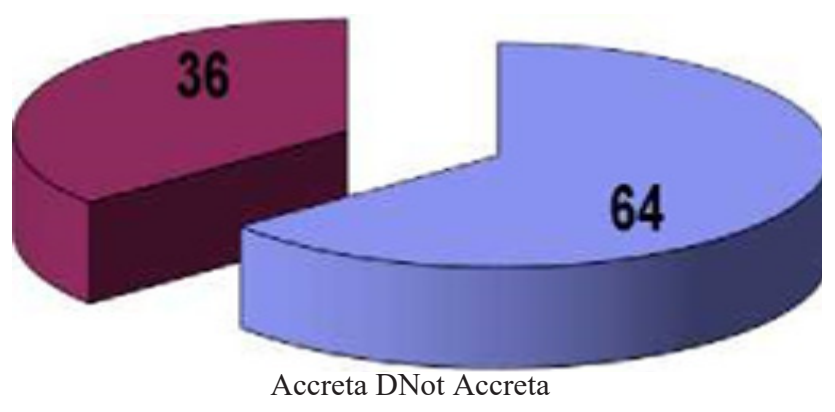

Fig. 2 : Types of placenta Intraoperatively between cases intra operative

Figure 2 displays that intra-operatively (64\%) of cases were placenta accreta whereas, $(36 \%)$ of them were placenta not accreta 
Table 3: Correlation between the preoperative diagnosis by 2D U.S, Color Doppler, MRI and the intraoperative findings of the placental attachment between cases

\begin{tabular}{|c|c|c|c|c|c|c|c|}
\hline \multicolumn{3}{|c|}{$\begin{array}{c}\text { Pre-operative findings of } \\
\text { placental attachment (no. of cases) }\end{array}$} & \multicolumn{3}{|c|}{ Intra operative findings (no. of cases) } & \multirow[b]{2}{*}{$\mathrm{X} 2$} & \multirow[b]{2}{*}{ P-value } \\
\hline & & & $\begin{array}{c}\text { True +ve } \\
\text { diagnosis } \\
\text { of placenta } \\
\text { accreta }\end{array}$ & $\begin{array}{c}\text { False +ve } \\
\text { diagnosis } \\
\text { of placenta } \\
\text { accreta }\end{array}$ & $\begin{array}{c}\text { False -ve } \\
\text { diagnosis } \\
\text { of placenta } \\
\text { accreta }\end{array}$ & & \\
\hline Doppler & Accreta & 76 & $\begin{array}{c}64 \\
(100.0 \%)\end{array}$ & $\begin{array}{c}12 \\
(33.3 \%)\end{array}$ & $\begin{array}{c}0 \\
(0 \%)\end{array}$ & 14.035 & $0.001 *$ \\
\hline 2D U.S. & $\begin{array}{c}\text { Accreta } \\
\text { Non Accreta }\end{array}$ & $\begin{array}{l}68 \\
32\end{array}$ & $\begin{array}{c}60 \\
(93.8 \%)\end{array}$ & $\begin{array}{c}8 \\
(22.2 \%)\end{array}$ & $\begin{array}{c}4 \\
(6.3 \%)\end{array}$ & 13.543 & $0.001 *$ \\
\hline M. R. I. & $\begin{array}{c}\text { Accreta } \\
\text { Non Accreta }\end{array}$ & $\begin{array}{l}64 \\
36\end{array}$ & $\begin{array}{c}48 \\
(75.0 \%)\end{array}$ & $\begin{array}{c}16 \\
(44.4 \%)\end{array}$ & $\begin{array}{c}16 \\
(25.0 \%)\end{array}$ & 4.670 & $0.030^{*}$ \\
\hline
\end{tabular}

Table 3 displays that color Doppler ultrasound is the most accurate mean of diagnosing placenta accreta as it diagnosed 76 cases to be accreta and out of them, 64 cases were true positive intraoperatively with its sensitivity was $100 \%$. No false negative casess were detetcted. $(P=0.001)$ Grey scale ultrasound diagnosed 68 cases as placenta accreta ; whereas, 60 cases of them were true positive intraoperatively with its sensitivity was $93.8 \%$. $(P=0.001)$ By using MRI, 64 cases were diagnosed as accreta only (48) cases of them were true positive intraoperatively with its sensitivity was $75 \%(P=0.030)$

Table 4 : Sensitivity, specificity, positive and negative predictive value by color Doppler, 2D ultrasound, MRI between cases

\begin{tabular}{lcccc}
\hline & Sensitivity & Specificity & $\begin{array}{c}+\mathrm{+ve} \\
\text { Predictive } \\
\text { value } \\
\text { (PPV) }\end{array}$ & $\begin{array}{c}\text { Predictive } \\
\text { value } \\
(\mathrm{NPV})\end{array}$ \\
\hline Doppler & $100 \%$ & $66.6 \%$ & $84.2 \%$ & $100 \%$ \\
2D U. S & $93.7 \%$ & $77.7 \%$ & $88.2 \%$ & $87.5 \%$ \\
M R I & $75 \%$ & $55.5 \%$ & $75 \%$ & $55.5 \%$ \\
\hline
\end{tabular}

Table 4 displays that diagnostic sensitivity for placenta accreta was $(100 \%)$ for color Doppler ultrasound and $(93.7 \%)$ for 2D ultrasound and $(75 \%)$ for MRI. Specificities were $(66.6 \%)$ for color Doppler U.S and $(77.7 \%)$ for $2 \mathrm{D}$ ultrasound and $(55.5 \%)$ for MRI. The positive predictive value was $(84.2 \%)$ for color Doppler ultrasound and $(88.2 \%)$ for $2 \mathrm{D}$ ultrasound and $(75 \%)$ for MRI. The negative predictive value was $(100 \%)$ for color Doppler ultrasound and $(87.5 \%)$ for $2 \mathrm{D}$ ultrasound and $(55.5 \%)$ for MRI.
Table 5: Surgical procedures done during delivery of cases

\begin{tabular}{|c|c|c|c|}
\hline $\begin{array}{l}\text { Intraoperative } \\
\text { findings of } \\
\text { placental } \\
\text { attachement } \\
\text { (No. of cases) }\end{array}$ & $\begin{array}{l}\text { Surgical } \\
\text { procedure } \\
\text { done }\end{array}$ & Number & Percentage \\
\hline $\begin{array}{l}\text { Non Accreta } \\
\text { (36 cases) }\end{array}$ & $\begin{array}{l}\text { Ordinary } \\
\text { C.S }\end{array}$ & 36 & $100 \%$ \\
\hline \multirow[t]{2}{*}{ Accreta (64 cases) } & $\begin{array}{l}\text { C.S. with } \\
\text { other } \\
\text { hemostatic } \\
\text { measures }\end{array}$ & 36 & $56.3 \%$ \\
\hline & Hysterectomy & 28 & $43.7 \%$ \\
\hline
\end{tabular}

Table 5 displays that caesarean section was done for all cases of study group, (36) cases $(100 \%)$ were delivered smoothly without complications and these cases were confirmed to be not placenta accrete., the other (64) cases were confirmed to be placenta accrete intraoperatively, (36) cases $(56.3 \%)$ of them were saved and treated conservatively and control of bleeding done by bilateral ligation of uterine arteries and sutures in placental bed in lower uterine.

As regards postoperative complications, 20 cases of the 100 study cases $(20 \%)$ were complicated by bladder injury during delivery and only 4 cases of the 100 study cases (4\%) were admitted to ICU postoperatively. 


\section{DISCUSSION}

Although ultrasound is the mainstay in the imaging of placenta accreta, MRI has been used as an adjunct in diagnosis when the ultrasound results are equivocal and/or clinical suspicion is high. Overall, in the present study, the diagnosis of abnormal attachment of the placenta to the myometrium was correct in $(100 \%)$ of cases for Doppler ultrasound and in $(75 \%)$ of cases for MRI.

In the present study, sensitivity for the diagnosis of placenta accreta was $(100 \%)$ for color Doppler ultrasound, (93.7\%) for 2D ultrasound and (75\%) for MRI. Specificity was (66.6\%) with color Doppler and $(77.7 \%)$ for $2 \mathrm{D}$ ultrasound and $(55.5 \%)$ for MRI. The highest positive predictive value (PPV) was found in 2D ultrasound (88\%), MRI had the lowest PPV (75\%), while color Doppler had 84\% PPV. Negative predictive value (NPV) was $(100 \%),(87.5 \%),(55.5 \%)$ for color Doppler, 2D ultrasound and MRI, respectively.

Color Doppler US diagnosed all cases to be accreta intraoperatively. Sensitivity (100\%), Grey scale US diagnosed (93\%) of cases found to be accreta intraoperatively and only 2 cases were negatively diagnosed not to be accreta. Sensitivity (93.7\%), and MRI diagnosed $(75 \%)$ of cases found to be accreta intraoperatively and 8 cases were negatively diagnosed not to be accreta. Sensitivity (75\%). Lake of MRI accuracy in diagnosis of placenta accreta may be due to improper interpretation of the findings.

So, the use of Grey scale Ultrasound and Color flow Doppler in all cases of placenta previa with previous C.S can detect or even suspect placenta accrete. MRI is a complementary method to Color Doppler Ultrasound in diagnosis of placenta accreta especially in cases with suspicious findings on ultrasonography

There was a significant difference in sensitivity and specificity between MRI and ultrasound. Compared with the literature, there was a better sensitivity and specificity of 2D ultrasound and color Doppler ultrasound than MRI for the diagnosis of placenta accrete.

There were many meta-analyses have considered the accuracy of ultrasound and MRI for the diagnosis of invasive placentation and a comparison of ultrasound and MRI. D'Antonio et al. reported a sensitivity of $(90.7 \%)$ for ultrasound and (94.4\%) for MRI and a specificity of $(96.9 \%)$ for ultrasound and (84\%) for MRI. ${ }^{[30]}$ Meng et al. showed that ultrasound sensitivity was $(83 \%)$, and its specificity was $(95 \%)$, compared with (82\%) and $(88 \%)$, respectively, for MRI. These meta- analyses reported that ultrasound and MRI are equally accurate in diagnosing the presence of invasive placentation $^{[31]}$. Vascularization perpendicular to the myometrium, a feature used by our teams had a positive predictive value of $84.2 \%$ and appears to be one of the most discriminating characteristics for the diagnosis of placenta accreta. It reflects the loss of the normal architecture of the vessels of the placenta with intra-placental hypervascularization and chaotic connections $^{[31]}$.

Other authors have also reported that abnormal vascularization seen by color Doppler ultrasound has the best combination of sensitivity and specificity and that its localization at the uterus-bladder interface has the best specificity in the prediction of invasive placentation $^{[32]}$.

Ultrasonography remains the most sensitive and commonly used imaging modality for the diagnosis of placenta accreta because it is accurate, inexpensive, and non-invasive and time-saving. MRI appears to be complementary to ultrasonography, especially when there are few ultrasound signs. Finally, Color Doppler Ultrasound is the most accurate imaging modality in the diagnosis of placenta accreta. Its accuracy, when combined with 2D Ultrasound, would increase and provides the best available modality for diagnosis of placenta accreta.

\section{CONFLICT OF INTEREST}

There are no conflicts of interest

\section{REFERENCES}

1. Miller D, Chollet JA, Goodwin TM: Clinical risk factors for placenta praevia-placenta accreta. Am J Obstet Gynecol: 1997; vol. 177:pp.210-214

2. Fitzpatrick KE, Sellers S, Spark P, Kurinczuk JJ, Brocklehurst $\mathrm{P}$, et al.:Incidence and risk factors for placenta accreta/increta/percreta in the UK: a national case-control study. 2012; PLOS ONE 7: e52893. doi: 10.1371/journal.pone.0052893

3. Khong TY.: The pathology of placenta accreta, a worldwide epidemic. J Clin Pathol 2008; vol61: pp.1243-1246.

4. Gielchinsky Y, Rojansky N, Fasouliotis SJ, Ezra Y.: Placenta accreta, summary of 10 years: a survey of 310 cases. Placenta 2002; vol.23: pp.210-214

5. Finberg HJ, Williams JW. Placenta accreta: prospective sonographic diagnosis in patients with placenta previa and prior cesarean section J Ultrasound Med 1992; vol 11:pp.333-343 
6. Tantbirojn P, Crum CP, Parast MM.: Pathophysiology of placenta accreta: the role of deciduas and extra villous trophoblasts. Placenta 2008; vol.29:pp.639-645

7. Jang DG, Lee GSR, Yoon JH, and Lee SG.: Placenta percreta-induced uterine rupture diagnosed by laparoscopy in the first trimester: case report. Int J Med Sci 2011; vol. 8: pp.424-427

8. Cox SM, Carpenter RJ and Cotton DB.: Placenta percreta: ultrasound diagnosis and conservative surgical management. Obstet Gynecol 1988; vol.71: pp.454-456

9. Belfort MA. : Placenta accreta. Am J Obstet Gynecol2010; vol.203: pp.430-439

10. $\mathrm{Wu}$ S., Kocherginsky M., and Hibbard J. U.:"Abnormal placentation: twenty-year analysis," Am. J Obstet Gynecol 2005; vol. 192, no.5, pp.1458-1461,

11. Tantbirojn P., Crum C.P., and Parast M.M.: "Pathophysiology of placenta accreta: the role of decidua and extravillous trophoblast," Placenta 2008; vol. 29, no. 7, pp.639-645,

12. Comstock CH.: Antenatal diagnosis of placenta accreta: a review. Ultrasound Obstet Gynecol 2005; vol. 26:pp.89-96.

13. Comstock C. H.: "Antenatal diagnosis of placenta accreta: a review," Ultrasound in Obstetrics and Gynecology 2005; vol. 26, no 1, pp. 89-96.

14. Alkazaleh F., Geary M., Kingdom J., Kachura J. R., and Windrim R.: "Elective non-removal of the placenta and prophylactic uterine artery embolization postpartum as a diagnostic imaging approach for the management of placenta percreta: a case report," Journal of Obstetrics and Gynecology Canada 2004; vol. 26, no. 8, pp. 743-746,

15. Wong H. S., Ying K. C., Zuccollo J., Tait J., and Pringle K. C.: "Evaluation of sonographic diagnostic criteria for placenta accreta," Journal of Clinical Ultrasound 2008; vol. 36, no. 9, pp. 551-559,

16. Chou MM, Ho ES and Lee YH.: Prenatal diagnosis of placenta previa accretes by transabdominal color Doppler ultrasound. Ultrasound Obstet Gynecol 2000; vol.15 no (1): pp.28-35

17. Shih J. C., Jaraquemada J. M.P., Su Y. N. et al.: "Role of three-dimensional power Doppler in the antenatal diagnosis of placenta accreta:comparison with gray-scale and color Doppler techniques,"
Ultrasound in Obstetrics and Gynecology 2009; vol. 33, no. 2, pp.193-203,

18. Levine D, Hulka CA, Ludmir J., et al.:Placenta accreta: evaluation with color Doppler US, power Doppler US, and MR imaging. Radiology 1997; vol. 205: pp.773-776.

19. Masselli G, Brunelli R, Casciani E, et al.: Magnetic resonance imaging in the evaluation of placental adhesive disorders: correlation with color Doppler ultrasound. EurRadiol. 2008; vol.18 no.(6): pp.1292-1299.

20. Hoffman-Tretin JC, Koenigsberg M, Rabin A, Anyaegbunam A.: Placenta accreta. Additional sonographic observations. J Ultrasound Med 1992; vol.11 no.(1): pp.29-34

21. Baughman WC, Corteville JE, Shah RR.: Placenta accreta: spectrum of US and MR imaging indings. Radiographics. 2008; vol.28 no.(7): pp.1905-1916

22. HudonL, Belfort MA, Broome DR. : Diagnosis and management of placenta percreta: a review. Obstet Gynecol Surv. 1998; vol.53 no. ( 8): pp. 509-517

23. Comstock $\mathrm{CH}$, Love $\mathrm{JJ} \mathrm{Jr}$, Bronsteen RA, et al.: Sonographic detection of placenta accreta in the second and third trimesters of pregnancy. Am J Obstet Gynecol. 2004; vol.190 no.(4): pp.1135-1140.

24. Lerner JP, Deane S, Timor-Tritsch IE.: Characterization of placenta accreta using Transvaginal sonography and color Doppler imaging. Ultrasound Obstet Gynecol. 1995; vol. 5 no. (3): pp. 198-201.)

25. Allahdin S, Voigt S, Htwe TT. : Management of placenta praevia and accreta. J Obstet Gynaecol. 2011; vol.31 no. (1): pp.1-6.

26. Chou MM, Tseng JJ and Ho ES.: The application of three-dimensional color power Doppler ultrasound in the detection of abnormal uteroplacental angioarchitecture in placenta praevia percreta. Ultrasound Obstet Gynecol 2002; vol. 19: pp. 625-627.

27. Levine D, Hulka CA, Ludmir J., et al. : Placenta accreta: evaluation with color Doppler US, power Doppler US, and MR imaging. Radiology 1997; vol. 205: pp.773-776.

28. Chou M, Ho E, Lu F., et al:: Prenatal diagnosis of placenta praevia/ accreta with color Doppler ultrasound. Ultrasound Obstet Gynecol 1992; vol. 2: pp. 293-296. 
29. Chou MM and Ho ES.: Prenatal diagnosis of placenta accreta with power amplitude ultrasonographic angiography. Am J Obstet Gynecol. 1997; vol.177: pp.1523-1525.

30. Levine D., Hulka C. A., Ludmir J., Li W., and Edelman R. R. : "Placenta accreta: evaluation with color Doppler US, power Doppler US, and MR imaging," Radiology 1997; vol. 205, no. 3, pp 773-776.

31. D'Antonio F, Iacovella C, Bhide A: Prenatal identification of invasive placentation using ultrasound: systematic review and metaanalysis. Ultrasound Obstet Gynecol: 2013; vol. 42: pp. 509-517.

32. Meng X, Xie L, Song W: Comparing the diagnostic value of ultrasound and MRI for placenta accreta: a systematic reviewand meta-analysis. Ultrasound Med Biol: 2013; vol. 39: pp. 1958-1965.

33. Cali' G, Giambanco L, Puccio G, Forlani F: Morbidly adherent placenta evaluation of ultrasound diagnostic criteria and differentiation of placenta accreta from percreta. Ultrasound Obstet Gynecol 2013; vol. 41: pp. 406-412. 